\title{
Acute Effect of Whole Body Vibration Training on Balance, Isokinetic Strength and Jump Performance
}

\section{Hilal Demir Usta, Berna Ramanli*, Ayşegül Yapici Öksüzoglu}

Faculty of Sport Sciences, Pamukkale University, Denizli, Turkey

Study Area: Denizli, Turkey

Coordinates: $37.739787^{\circ} \mathrm{N} ; 29.101539^{\circ} \mathrm{E}$

Key words: Sport training, Sensoriomotor, Sports techniques, Sports skill

\section{Abstract}

The whole body vibration training, which has become popular in recent years, is a method applied in combination with training and is recommended for increasing the performance of the athlete.The aim of this study is to investigate the acute effect of whole body vibration training on balance, isokinetic strength and jump in volleyball players. University volleyball team player $(n=12)$ voluntarily completed the whole body vibration training protocol. Before each measurement, the athletes were warmed up on the bicycle ergometer. Balance, isokinetic strength and jump tests were applied to the athletes on the first day. Before the tests performed on the 4 th, 7 th and oth days, the athletes performed the dynamic squat exercise on the vibration platform. After the application, static and dynamic balance measurements (4th day), isokinetic strenght measurements (7th day) and active jump measurements (1oth day) were performed.In the analysis of the data, the suitability of the parameters to the normal distribution was evaluated using the Shapiro-Wilk test.In addition, the skewness and kurtosis values were also examined to see if the data showed a normal distribution. As per results, while the tracking error in the dynamic test result decreased from the balance test parameters, there was no significant difference in other parameters. In addition, there was no significant difference in jump and isokinetic strength measurements.It can be said that whole body vibration training applied to volleyball players has no acute effect on balance, jumping and isokinetic strength.

make a difference in the effect of vibration according to the person applied, the duration, and the method of the application. Because of its ease of use and requires little technical skills, the use of vibration is applied to athletes by being modified with various training in the field of sports, and to patients for rehabilitation (Ramanli et al., 2017; Koç \& Erman, 2012). Vibration is applied to the body in two ways. In the first method, it is applied directly to the tendon of the muscle to be trained, while in the second method it is applied indirectly-Whole Body Vibration Training (WBVT) - (Luo et al., 2005). WBVT creates a vibration that can affect the whole body, bones, and muscles of a person climbing on a platform (Koç\& Erman, 2012).

Considering the studies on the usage areas of vibration, while the results of the studies on warm-up (Bush et al., 2015; Cochrane \& Stannard, 2005), flexibility (Jemni et al., frequency and amplitude. These two variables in vibration

*Corresponding Author: bramanli@pau.edu.tr 
2014; Kin Isler, 2007) and balance (Despina et al., 2014) are positive, researches on neuromuscular performance (Kin Isler, 2007), hormonal and metabolic events (Gyulai et al., 2013) and changes in blood circulation are still insufficient.

Volleyball is a team sport that requires skill and conditioning features such as high-level endurance, strength, flexibility, speed, quickness, mobility, balance, reaction, and strategy (Özkan et al., 2010; Berg et al., 1985). Sprints jump (block and spike) and repeated high-intensity movements during the match increase the importance of the neuromuscular system (Özkan et al., 2010). Jumping too high in block and spike movements is important in success (Çon et al., 2012). Jumping is closely related to the strength of the lower extremity flexor and extensor muscles. The balance should not be regarded as the basic component independent of jumping and strength. For the volleyball players to be successful on the field, it is necessary to gain strength and maintain this power, as well as to provide body control with appropriate mechanics, that is, balance control must be good (Ibis et al., 2015). The coordinated movement of the whole body as a whole occurs in direct proportion to the skill of balance. (Erdogan et al., 2017). The strength of the lower extremity also plays an important role in the success of the game. Considering the muscle strength, it can be said that explosive muscle contractions caused by knee extensors are a very important part of the anaerobic performance of athletes (Özkan \& Kin Isler, 2010). As a result, the importance of muscle strength and balance in jumping is great. This study aims to determine the acute effect of WBVT on balance, isokinetic strength, and jump performance in male volleyball players.

\section{Materials and Methods:}

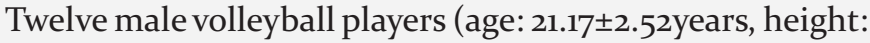
$1.81 \pm 0.05 \mathrm{~cm}$, weight: $85.67 \pm 13.85 \mathrm{~kg}$, body mass index: $26.11 \pm 4.73 \mathrm{~kg} / \mathrm{m}^{2}$ ) participated in this study voluntarily. To control the training, the research group was limited to the players of a single team. All athletes had 8-9 years of training and competition experience. Athletes trained 2 hours/day, 3 days/week. Athletes had no previous experience with WBVT. All athletes were informed about the study, their informed consent was obtained, and randomization was performed one week before the measurements. Participants were asked not to drink alcohol and exercise with high intensity during the study and 24 hours before the pre-tests. Approval was obtained from Pamukkale University, Non-Interventional Clinical Research Ethics Committee for the research (60116787020/4306-17.01.2018).

The research was completed in 10 days in total, with an interval of 48 hours. In all practice days, firstly, the study group was warmed up with a 5-minute bicycle ergometer (Monomark). After warming up, WBVT protocol was applied. In this protocol balance, jump, and isokinetic strength tests were applied to the participants on 1st day for pre-test data. On the 4 th, 7 th, and 1oth days, they performed the dynamic squat exercise (6osec vibration $x$ 5 sets $\mathrm{x}$ 30sec rest between each set) on the vibration platform $(30 \mathrm{~Hz}-4 \mathrm{~mm})$. After the application, static and dynamic balance measurements (4th day), isokinetic strength measurements (7th day), and active jump measurements (1oth day) were performed and the final test data were collected. Post-test data were taken immediately aftervibration was applied.

Data collection was done in Pamukkale University Faculty of Sport Sciences Performance Laboratory. Anthropometric measurements consist of height, weight, and body mass index. Measurements were carried out with the Height and Body Weight Measurement Device (SECA, Germany). TecnoBody Pro-Kin B PK-212 balance system was used in the balance measurement. For the static balance test, the participants completed the 30 seconds by keeping the "+" sign seen on the monitor as static as possible with open eyes. In the dynamic balance test, an unstable platform was created by moving the platform in mediallateral and anterior-posterior directions. The test was completed by following the circular route on the screen and rotating the platform 5 rotations clockwise within 60 seconds. Isokinetic Strength Measurement was applied to the lower extremities with Cybex (Humac norm 770 USA). Concentric knee flexion-extension muscle strength measurements from the dominant-non-dominant legs were performed with 5 repeats at concentric $60 \%$ and 5 repeats at concentric $180 \%$ s. The Jump Performance was evaluated by the active jump test. A jump mat (FUSIONSPORT-SMARTJUMP) was used to measure the active jump height. The test was applied twice, 30 seconds of rest was given between tests and the best grade was recorded. Power Plate vibration platform (Pro5 Airdaptive) was used in the WBVT.

All statistical analyzes were performed at 0.05 significance level with the SPSS package program. First, descriptive statistics of the data were carried out. In the analysis of the data, the suitability of the parameters to the normal distribution was evaluated using the Shapiro-Wilk test. Besides, the skewness and kurtosis values were also examined to see if the data showed normal distribution. George and Mallery accept that the distribution occurs as a normal distribution when the skewness and kurtosis values are between $+2,000$ and -2,00o (George \& Mallery, 2010). The data showed normal distribution because the skewness and kurtosis values were between $+2,000$ and $-2,000$. As a result, the Paired Samples T-Test was applied.

\section{Results:}

When the static balance test data were compared, no statistically signif icant difference was found ( $\mathrm{p}>0.05$ ). When the dynamic balance test data were compared, a statistically significant difference was found in the 
dynamic average tracking error $(\mathrm{p}=0.045)$, while no statistically significant difference was found in other parameters ( $\mathrm{p}>0.05)$.

Table-1: Pre-Post Test Measurement Values Obtained from Balance Measurements

\begin{tabular}{|c|c|c|c|c|c|}
\hline $\begin{array}{l}\text { Paramet } \\
\text { Pre-Test } \\
\text { mean }\end{array}$ & Ss & $\begin{array}{l}\text { Post-Tes } \\
\text { mean }\end{array}$ & & $\mathrm{T}$ & $\mathrm{p}$ \\
\hline \multicolumn{6}{|c|}{ Static anterior-posterior oscillation } \\
\hline \multicolumn{6}{|c|}{ Static right-left oscillation } \\
\hline \multicolumn{6}{|c|}{ Static anterior-posterior oscillation velocity $(\mathrm{mm} / \mathrm{sec})$} \\
\hline $\begin{array}{l}15.00 \\
\text { Static rio }\end{array}$ & $\begin{array}{l}4.24 \\
\text { t-left }\end{array}$ & $\begin{array}{l}13.58 \\
\text { ation vel }\end{array}$ & $\begin{array}{l}2.72 \\
\text { locity }\end{array}$ & $\begin{array}{l}1.620 \\
\mathrm{n} / \mathrm{sec})\end{array}$ & 0.133 \\
\hline 11.67 & 3.68 & 10.25 & 2.30 & 1.468 & 0.170 \\
\hline \multicolumn{6}{|c|}{ Static scanned area $\left(\mathrm{mm}^{2}\right)$} \\
\hline \multicolumn{6}{|c|}{ Dynamic stabilization indicator $\left(^{\circ}\right)$} \\
\hline 0.93 & 0.39 & 0.93 & 0.26 & -0.007 & 0.995 \\
\hline \multicolumn{6}{|c|}{ Dynamic average tracking error $(\%)$} \\
\hline \multicolumn{6}{|c|}{ Dynamic average strength variance $(\mathrm{kg})$} \\
\hline 0.33 & 9.06 & -1.22 & 7.00 & 0.468 & 0.649 \\
\hline
\end{tabular}

Table-1: Pre-Post Test Measurement Values Obtained from Isokinetic Measurements

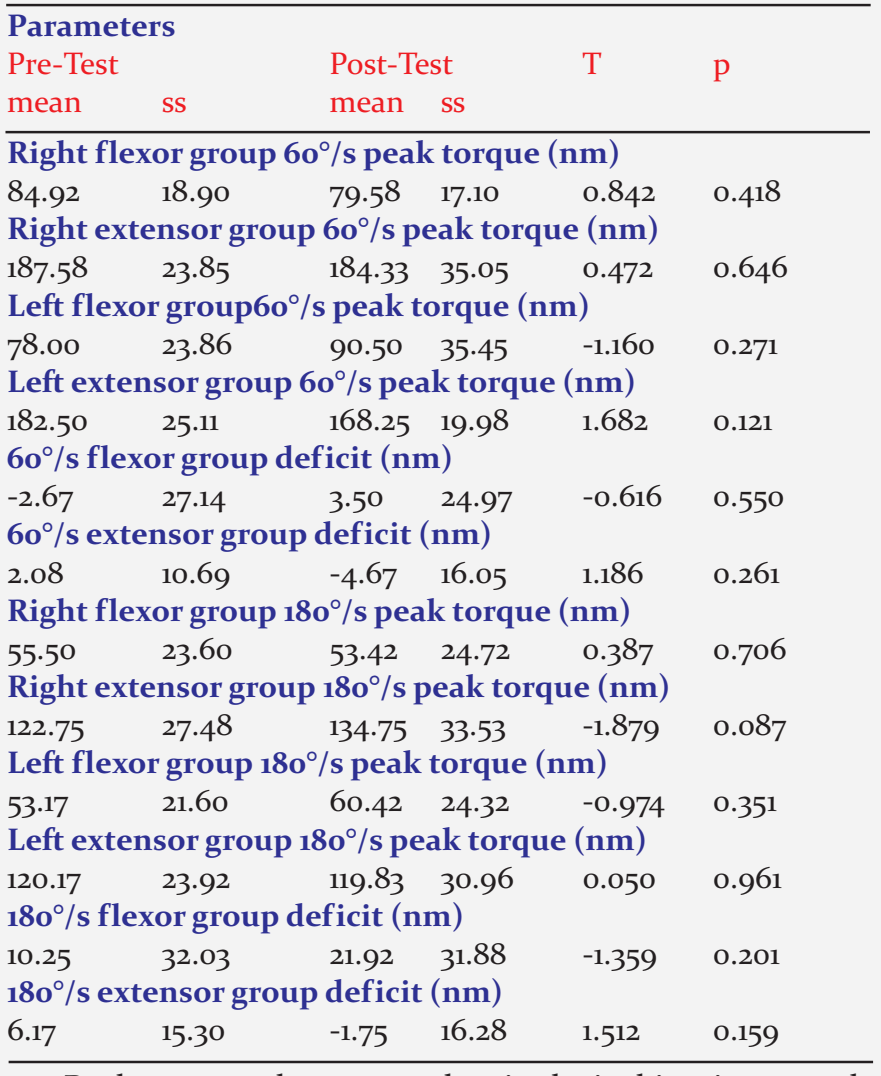

Peak torque values were taken in the isokinetic strength measurements of the athletes. No significant difference was found according to the test results obtained by applying $60^{\circ} / \mathrm{s}$ and $180^{\circ} / \mathrm{s} 5$ repetitions in the right and left legs ( $>>0.05)$. In addition, deficit values for flexion and extension muscles were also evaluated, but no statistically significant difference was found ( $p>0.05$ ).

Table-1: Pre-Post Test Measurement Values Obtained from Balance Measurements

\begin{tabular}{lllllll}
\hline Parameters & \multicolumn{2}{c}{ Pre-Test } & \multicolumn{2}{c}{ Post-Test } & \multirow{2}{*}{ T } & \multirow{2}{*}{ p } \\
& mean & ss & mean & ss & & \\
\hline Jump height $(\mathbf{c m})$ & 36.34 & 5.15 & 37.83 & 4.45 & -1.721 & 0.113
\end{tabular}

There was no statistically significant difference in active jump heights of volleyball players ( $p>0.05$ ). Although there was no statistically significant difference in active jump heights, an increase was found in the values when the averages were examined.

\section{Discussion:}

Based on the results, it could be said that WBVT applied has no effect on balance, Isokinetic force, and jumping, except for the dynamic average tracking error in the dynamic balance test.

The only significant difference in the static and dynamic balance tests was that the mean tracking error in the dynamic test result was reduced $(\mathrm{p}=0.045)$. Although the change in other parameters was not statistically significant, a decrease was observed in other parameters except the dynamic stabilization indicator. In line with these results, it can be said that WBVT used in this study did not have an acute effect on balance performance, but there was an improvement in balance values. When the literature was examined, it was seen that the last measurements for the acute effect were measured immediately after WBV or repeatedly at certain intervals in the studies examining the balance performance, thus it was emphasized how sustainable the effect was. In this study, the final test balance was measured 30 seconds after WBVT. When studies similar to this study and investigating the acute effect of WBV on balance were examined, it was seen that similar and different results were obtained. Our results confirm the previous finding of Kaçoğlu \& Gürol (2016). They performed the static squat exercise in 2 sets of 60 seconds WBVT $(30 \mathrm{~Hz}-2 \mathrm{~mm})$ and could not find a statistically significant difference in the balance test performed after 3 minutes and 5 minutes. There are also studies indicating that WBVT has positive acute effects on balance. In another study conducted on athletes, a balance test was applied immediately after and 15 minutes after acute vibration training $(30 \mathrm{~Hz}-2 \mathrm{~mm})$ involving dynamic squat, and it was reported that there was an increase in balance performance-tested 15 minutes later (Despina et al., 2014). Besides, they stated that acute vibration training (static squat $3 \times 605 e c, 40 H z-4 \mathrm{~mm}$ ) increased balance in elite and amateur male soccer players and interpreted that this could be due to a possible increase in flexibility (Cloak 
et al., 2016). It was concluded that the form of acute vibration training applied with these parameters $(5 \times 60 s e c$, $30 \mathrm{~Hz}-4 \mathrm{~mm}$ ) did not provide adaptation to improve balance ability in volleyball players.

The change in isokinetic strength parameters was not statistically significant. In this study, 5 repetitions at concentric $60 \%$ and 5 repetitions at concentric $180 \%$ s test protocols were used in the isokinetic strength test. Besides, dynamic squat exercise was applied for 60 seconds in WBVT. Because many studies have combined dynamic squat exercise with vibration in WBVT, and they concluded that this practice combined with dynamic squat positively affects neuromuscular functioning. They also stated that this combination can be used as a warming protocol. When these studies similar to our study and investigating the acute effect of WBV on isokinetic strength were examined, it was seen that similar and different results were obtained. Our results confirm the previous finding of Yeung et al., (2014). They concluded that WBVT (45 Hz) applied for 3 minutes had no acute effect on peak torque. However, some studies found that WBVT has positive acute effects on isokinetic strength. Bush et al., (2015) evaluated the isokinetic leg strength in their study which applied to 21 healthy participants from 4 protocols (Protocolı: 10 dynamic squat-5sets without vibration; Protocol2: static squat without vibration for 30sec-5sets; Protocol3: $2.5 \mathrm{~min}$ $30 \mathrm{~Hz}$ WBV 10 dynamic squats- 5sets; Protocol4: 2.5min $30 \mathrm{~Hz}$ WBV 30 sec static squat-5sets). As a result, while finding an increase in the 3 rd protocol, they found a decrease in strength in other protocols and emphasized that the combination of dynamic squat and vibration is important for increasing leg strength. In the study conducted by Siu et al., (2010), the effect of short-term WBVT applied in two different protocols as $26 \mathrm{~Hz}-4 \mathrm{oHz}$ on knee extension and flexion peak torque was investigated. Participants stood on the WBV platform in a static halfsquat position 10 times for 6o seconds. Isokinetic strength measurement applied 5 repetitions at $60^{\circ} / \mathrm{sec}$, was made immediately after WBVT. They found that there was a statistically significant difference in the knee extension peak torque variable in both WBV protocols $(\mathrm{p}<0.05)$. Our research has shown that the application of dynamic squat protocol with 5 sets of WBV ( $30 \mathrm{~Hz}-4 \mathrm{~mm}$ ) consisting of 60 seconds does not affect the highest torque performance in male volleyball players. The reason for this may be that after WBVT in our study, most of the participants complained of lower extremity muscle fatigue. It is unclear whether this feeling of fatigue affects participants' determination to generate the highest torque powergeneration.

As a result of the jump performance test, there was no significant difference between pre-test and post-tests. However, it was observed that there was an increase in jump height. Therefore, it can be said that WBVT used in this study has no acute effect on jump performance, but there is an improvement in jump height values. When studies similar to our study and investigating the acute effect of $\mathrm{WBV}$ on isokinetic strength were examined, it was seen that similar and different results were obtained. Our results confirm the previous finding of Torvinen et al., (2002b). In their studies, they had dynamic squats for 4 minutes in their WBVT (25-40Hz-2mm) and found no significant difference in active jump height compared to the control group. However, some studies have found that WBVT has positive acute effects on jumping performance. Cochrane \& Stannard (2005) divided 16 elite women into 3 groups. He applied dynamic squat, static squat, and lunge exercises with WBV (26Hz-6mm, 6osec, 5sets) to the 1st group, dynamic and static squat exercises without WBV to the 2nd group, and cycling $(5 \mathrm{~W}, 5 \mathrm{~min})$ exercises to the 3 rd group. And as a result, they achieved a significant increase in active jump height of $8.1 \%$ in the vibrating group. In another study by Cochrane et al., (2008) investigating the effect of WBV on jump height, they again divided the participants into 3 groups. Dynamic squats $(26 \mathrm{~Hz}-6 \mathrm{~mm}, 60 \mathrm{sec}, 5$ sets) were applied to the first group, pedaling ( $70 \mathrm{~W}-10 \mathrm{~min})$ to the second group, and a hot bath $\left(41^{\circ} \mathrm{C}, 17 \mathrm{~min}\right)$ to the third group. As a result, there was an increase in active jump height in all 3 groups. There were no significant differences between the groups. In the study of Torvinen et al., (2002a), a $2.5 \%$ increase in active jump height was observed with the WBVT $(15-30 H z, 10 m m)$ applied. In another study, a protocol was applied in which WBV applied for 6o seconds at $26 \mathrm{~Hz}$ frequency was repeated with 60 seconds of rest breaks, and it was found that this program increased strength, power, and speed performance in elite female volleyball players (Bosco et al., 1999).

\section{Conclusion:}

Considering the literature, it can be said that these conflicting results are due to differences in WBVT, exercise protocol, frequency, and amplitude. Also, characteristics of the participants, such as age, training age, and gender, may have affected the results. Because every person's response to vibration can vary from person to person. As a result, WBV protocol $(5 \times 60 s e c, 30 \mathrm{~Hz}-4 \mathrm{~mm})$ has no acute effect on balance, isokinetic strength, and jumping performance in male volleyball players. In future studies, more athletes can be reached and different results can be obtained with different training protocols.

\section{Acknowledgments:}

This study was supported by Pamukkale University Scientific Research Projects Coordination Unit (Project Number:2018SABE029) which pro $\neg$ vided financial and equipment support. We would like to thank all the athletes who volunteered for this study.

\section{References:}

Berg, K.E., LaVoie, J.C. \& Latin, R.W. (1985): Physiological training effects of playing youth soccer. Med. Sci. Sports Exer., 
$17(6): 656-660$.

Bosco, C., Colli, R., Introini, E., Cardinale, M., Tsarpela, O., Madella, A., Tihanyi, J. \& Viru, A. (1999): Adaptive responses of human skeletal muscle to vibration exposure. Clinical Physiol., 19(2):183.

Bush, J.A., Blog, G.L., Kang, J., Faigenbaum, A.D. \& Ratamess, N.A. (2015): Effects of quadriceps strength after static and dynamic whole-body vibration exercise. L. Strength Cond. Res., 29(5):1367-1377.

Cardinale, M. \& Bosco, C. (2003): The use of vibration as an exercise intervention. Exer. Sport Sci. Rev., 31(1):3-7.

Cloak, R., Nevill, A. \& Wyon, M. (2016): The acute effects of vibration training on balance and stability amongst soccer players. Eu. J. Sport Sci., 16(1):20-26.

Cochrane, D.J. \& Stannard, S.R. (2005): Acute whole body vibration training increases vertical jump and flexibility performance in elite female field hockey players. Br. J. Sports Med., 39(11):860-865.

Cochrane, D.J., Stannard, S.R., Sargeant, A.J. \& Rittweger, J. (2008): The rate of muscle temperature increase during acute wholebody vibration exercise. Eu. J. Appl. Physiol., 103(4):441-448.

Çon, M., Akyol, P., Tural, E., \& Tasmektepligil, M.Y. (2012): The Effect of Flexibility and Body Fat Percentage on Vertical Jump Performance with Volleyball Players. Selçuk Uni. J. Phy. Edu. SportSci., 14(2):202-207.

Despina, T., George, D., George, T., Sotiris, P., George, K., Maria, R. \& Stavros, K. (2014): Short-term effect of whole-body vibration training on balance, flexibility and lower limb explosive strength in elite rhythmic gymnasts. Hum. Mov. Sci., 33:149-158.

Erdogan, C.S., Fatmanur, E.R., Ipekoglu, G., Çolakoglu, T., Zorba, E. \& Çolakoglu, F.F. (2017): The Effects of Different Type Balance Exercises on Static and Dynamic Balance Performance in Volleyball Players. J. Sports Perf. Res., 8(1):1118.

Ergin, E. \& Yücel, S.B. (2011): Acute Effects of Stretching Exercise Modalities on Upper and Lower Extremity Strength Parameters. Turk. J. Sports Med., 46(4):145-153.

George, D. \& Mallery, M. (2010): SPSS for Windows Step by Step: A Simple Guide and Reference. 17.0 update (10a ed.). Pub. by: Boston: Pearson.

Griff in, M.J. (1996): Handbook of Human Vibration. Pub. by: London: Academic Press, Harcourt Brace \& Company Publishers.

Gyulai, G., Rácz, L., DiGiminiani, R. \& Tihanyi, J. (2013): Effect of whole body vibration applied on upper extremity muscles. Acta Physiol. Hungarica, 100(1):37-47.

Ibis, S., Iri, R. \& Aktug, Z.B. (2015): The effect of female volleyball players' leg volume and mass on balance and reaction time. $J$. Human Sci., 12(2):1296-1308.
Jemni, M., Mkaouer, B., Marina, M., Asllani, A. \& Sands, W.A. (2014): Acute static vibration-induced stretching enhanced muscle viscoelasticity but did not affect maximal voluntary contractions in footballers. L. Strength Cond. Res., 28(11):31053114.

Kaçoglu, C. \& Gürol, B. (2016): Effect of body position during whole body vibration on acute jumping performance. Baltic J. Sport Health Sci., 3(102).

Kin Isler, A. (2007): Effects of vibration on performance. Hacettepe L. Sport Sci., 18(1):42-56.

Koç, G. \& Erman, K.A. (2012): The neurophysiological effects of whole body vibration training. Nigde Uni. J. Phy. Edu. Sport Sci., 6(2).

Luo, J., McNamara, B. \& Moran, K. (2005): The use of vibration training to enhance muscle strength and power. Sports Med., 35(1):23-41.

Özkan, A. \& Kin Isler, A. (2010): The Association among leg volume, leg mass and $\mathrm{H} / \mathrm{Q}$ ratio with anaerobic performance and isokinetic knee strength in athletes. Hacettepe J. Sport Sci., 21(3):90-102.

Özkan, A., Köklü, Y., Eyuboglu, E., Akça, F., Koz, M. \& Ersöz, G. (2010): The determination of relationship between body composition, somatotype, anaerobic performance, leg and back strength in female volleyball players. Gazi J. Phy. Edu. SportSci., 15(4):23-34.

Ramanli, B., Toraman, N.F., Aktop, A., Toktas, N., Basrali, F. \& Kacar, G. (2017): The effects of whole body vibration training on physical performance, body composition and bone mineral density in osteoporosis. Int. J. Recent Sci. Res., 8(11):21673-21682.

Siu, P.M., Tam, B.T., Chow, D.H., Guo, J.Y., Huang, Y.P., Zheng ,Y.P. \& Wong, S.H. (2010): Immediate effects of 2 different wholebody vibration frequencies on muscle peak torque and stiffness. Arc. Phy. Med. Rehabilitat., 91(10):1608-1615.

Torvinen, S., Kannus, P., SievaÈnen, H., JaÈrvinen, T.A., Pasanen, M., Kontulainen, S., Järvinen, T.L.N., Järvinen, M., Oja, P. \& Vuori, I. (2002a): Effect of a vibration exposure on muscular performance and body balance. Randomized cross-over study. Cli. Physiol. Functional Imag., 22(2):145-152.

Torvinen, S., Sievänen, H., Järvinen, T.A.H., Pasanen, M., Kontulainen, S. \& Kannus, P. (2002b): Effect of 4-min vertical whole body vibration on muscle performance and body balance: a randomized cross-over study. Int. J. Sports Med., 23(05):374-379.

Yeung, E.W., Lau, C.C., Kwong, A.P., Sze, Y.M., Zhang, W.Y. \& Yeung, S.S. (2014): Acute whole-body vibration does not facilitate peak torque and stretch reflex in healthy adults. $L$. Sports Sci.Med., 13(1):3 